\title{
Using Grey Production Functions in the Macroeconomic Modelling: An Empirical Application for Romania
}

\author{
Ana Michaela ANDREI, Irina GEORGESCU \\ Department of Economic Informatics and Cybernetics \\ Bucharest University of Economic Studies, Romania \\ aaeconomy@gmail.com, irina.georgescu@csie.ase.ro
}

The work is a development of our earlier studies containing empirical application of models with representative agent. The extensions developed in this paper consist of the following: the introduction of the labor market via the use of labor as the second production factor, the use of the $G M(1,1)$ algorithm in order to adjust the capital and labor data series and to compute grey Cobb-Douglas production function, and finally the comparison of the results obtained applying the model to the actual data and the grey data. The grey production function is estimated using $G M(1,1)$ adjusted statistical series of the GDP, capital stock and labor data. For the two variants we computed the predictions of the indicators: real GDP, consumption, government expenditures, trade balance, and burden of debt.

Keywords: Representative Agent Model, Production Function, Current Account, Trade Balance, Grey Systems

\section{Introduction}

In the macroeconomic theory, "representative agent" model is a mean to provide the aggregate behavior of the economy based on microeconomic optimization of the agents.

Macroeconomic behavioral relationships are derived using inter-temporal optimization of microeconomic agents. This approach belongs to the New Classical Macroeconomic School that has great success around 1970s.

Nevertheless this approach can generate some controversial aspects, such that the aggregation and the Pareto consistency problems of the representative agents problems [1].

Another aspect to be controversy is the fact that most of the literature employing representative agents framework is deterministic, stochastic intertemporal optimization is difficult and often very formal. Hansen and Sargent [2] formulated a justification of the use of these models that consist of possible consistency between their solutions with the solutions of the aggregated optimal decision models and of the general equilibrium models.

The analysis made by Hartley in [3] leads to the conclusion that the representative agent models cannot describe adequately the macroeconomic aggregate behavior. In [4] Kirman holds back against the representative agent, since the choices of the agents are not homogeneous and their reaction to changes are not the same. Other controversial issues on the representative agent can be found in ([5], [6]).

This research fields is still subject to research: [7], [8]. Recently Krueger [9] extends the representative agent approach building economic cyclicality models with agents of the same type (households and firms) and uses them in business cycle analysis.

A possible alternatives to the approach of representative agent in economics would be agent-based simulation models. In agentbased computational economics, an agent is a physical or virtual entity [10] which acts in a specified environment, communicates with other agents, follows a set of trends representing goals or optimizes a function, etc. Agent-based models are based on autonomous agents which interact with one another according to a set of rules of behavior [11]. The applications lie in a large area such as: modeling agent behavior in the stock markets and supply chains, modeling consumer behavior, predictions etc. [12]. 
In many situations, the assumption of a representative household is not appropriate according to Acemoglu [13] because households do not have an infinite planning horizon and because new households arrive (or are born) over time. Decisions made by older generations will affect the prices faced by younger generations, so, besides the neoclassical growth model, the "overlapping generations' model" is the second great result of research into modern macroeconomics.

We use this type of modes due to the facile application on statistical data in order to compute some macroeconomic indicators and to forecast them [14], [15], [16].

We organized the paper in six sections beginning with the introduction, continuing with general formulation of the model, solving the model with actual data and grey data, empirical application and the comparison of the results of the two approaches, and final conclusions and further topics.

\section{Open Economy Extended With Labor Market and Investments}

We extend the analysis made in our previous paper [14], considering two production factors, labor and capital, so that the technology follows a neoclassic production function:

$Y_{s}=A_{s} F\left(K_{s}, L_{s}\right)$,

with $L_{s}$ the labor at the time $s, K_{s}$ is the physical capital at the time $s$, and $F\left(K_{s}, L_{s}\right)$ has decreasing returns to scale.

Assume that the representative firm behaves competitively and it is owned entirely by domestic residents.

The consumer's problem consists of the maximization of the sum of the present discounted values of the utilities, on the infinite periods of time:

$U_{t}=\sum_{s=t}^{\infty} \beta^{s-t} u\left(C_{s}\right)$

subject to the budget constraint (Honkapoja [17]):

\section{Representative Agent Model for a Small}

$B_{s+1}-B_{s}+V_{s} x_{s+1}-V_{s-1} x_{s}=r B_{s}+d_{s} x_{s}+\left(V_{s}-V_{s-1}\right) x_{s}+w_{s} L-C_{s}-G_{s}$.

where $w_{s}$ are the wages the firm hires the labor at period s;

$V_{s}$ is the price of the claim to the firm's entire profits from the period $(s+1)$ onwards;

$x_{s+1}$ is the share of the domestic firm in the private propriety of the consumer at the end of the date $s ; d_{s}$ is the dividend the firm at the end of the date $s ; B_{s}$ are the net foreign assets in period $s ; G_{s}$ denotes the government consumption, period $s ; C_{s}$ is the consumption in period $s ; r$ is the world interest rate.

The first order conditions are given by:

a) Euler equation:

$$
u^{\prime}\left(C_{s}\right)=(1+r) \beta u^{\prime}\left(C_{s+1}\right)
$$

and the new Euler equation:

b) $V_{s} u^{\prime}\left(C_{s}\right)=\left(V_{s+1}+d_{s+1}\right) \beta u^{\prime}\left(C_{s+1}\right)$

(4), (5) imply:

$$
1+r=\frac{d_{s+1}+V_{s+1}}{V_{s}} .
$$

$r$, is the international interest rate, assuming this is constant in time.

The firm's market value on date $t$ is the present discounted value of the dividends it will pay to shareholders over the future, starting the date $(t+1)$. For this reason, we will sometimes call $V_{t}$ the firm's ex dividend market value on date $t$.

$V_{t}=\sum_{s=t+1}^{\infty}\left(\frac{1}{1+r}\right)^{s-t} d_{s}$

provided that:

$\lim _{T \rightarrow \infty}\left(\frac{1}{1+r}\right)^{T} V_{t+T}=0$

This condition often is called "no-bubbles" condition.

From (5) we obtain: 
$V_{t} u^{\prime}\left(C_{t}\right)=\sum_{s=t+1}^{\infty} \beta^{s-t} u^{\prime}\left(C_{s}\right) d_{s}+\lim _{T \rightarrow \infty} \beta^{T} u^{\prime}\left(C_{t+T}\right) V_{t+T}$.

At optimum, the second term must be 0 , so:

$V_{t}=\sum_{s=t+1}^{\infty} \beta^{s-t} \frac{u^{\prime}\left(C_{s}\right)}{u^{\prime}\left(C_{t}\right)} d_{s}=\sum_{s=t+1}^{\infty}\left(\frac{1}{1+r}\right)^{s-t} d_{s}(10)$.

Because $u^{\prime}\left(C_{t}\right)>0$ and

$\beta^{T} u^{\prime}\left(C_{t+T}\right)=u^{\prime}\left(C_{t}\right)(1+r)^{-T} \quad$ we obtain another form of the condition ,without bubbles".

Considering $d_{s}=d_{0}=$ constant, and applying the sum of the infinite geometric series in (10), we obtain:

$V_{0}=\frac{d_{0}}{r}$

In order to introduce the firm's behavior, consider the firm's dividends as output less salaries and investments:

$d_{s}=Y_{s}-w_{s} L_{s}-I_{s}$

with $I_{s}=K_{s+1}-K_{s}$, the investments function.

The firm maximizes the current and future dividends:

$\max \left\{\sum_{s=t}^{\infty}\left(\frac{1}{1+r}\right)^{s-t}\left[A_{s} F\left(K_{s}, L_{s}\right)-w_{s} L_{s}-\left(K_{s+1}-K_{s}\right)\right]\right\}$

where $w_{s}$ is the wage per person in the period $s$.

The first optimum conditions are:

$$
\begin{aligned}
& A_{s} F_{K}^{\prime}\left(K_{s}, L_{s}\right)=r, s>t \\
& A_{s} F_{L}^{\prime}\left(K_{s}, L_{s}\right)=w_{s}, s \geq t .
\end{aligned}
$$

The above conditions have the well-known significance from microeconomics: the equilibrium of the firm is obtained as long as the marginal product equals the marginal cost of production factors.
The current account equals national savings less investments, so, for our model, the equation of current account is:

$C A_{t}=S_{t}-I_{t}=r\left(B_{t}+V_{t-1} x_{t}\right)+w_{t} L_{t}-G_{t}-C_{t}$ (16)

The economy's trade balance is:

$T B_{t} \equiv Y_{s}-C_{s}-I_{s}-G_{s}$

and

$\frac{T B_{s}}{Y_{s}}=\frac{1}{Y_{s}}\left(Y_{s}-C_{s}-I_{s}-G_{s}\right)$

is the proportion of debt to GDP

The current account deficits are sustainable if they will satisfy the relation ([17]):

$T B_{t}=\sum_{s=t}^{T}\left(\frac{1}{1+r}\right)^{s-t}\left(Y_{s}-G_{s}-C_{s}-I_{s}\right)$

\section{The Analytic Solution of the Model Using Logarithmic Utility Function and Cobb- Douglas Production Function}

We considered a macroeconomic utility function of the form:

$U=\sum_{s=t}^{\infty} \log C_{s}$

and two factor Cobb-Douglas production function,

$Y_{s}=A_{s} K_{s}^{\alpha} L_{s}^{\gamma}$

with $\alpha$ being the elasticity of output with respect to physical capital stock, $\gamma$ the elasticity of output with respect to labor.

$A_{s+1}=(1+g)^{(\sigma-1)} A_{s}$

gives the dynamics of technological progress, with the solution:

$A_{s}=(1+g)^{s(\sigma-1)} A_{0}$

\section{The consumer's problem:}

$$
\left\{\begin{array}{l}
\max \sum_{s=t}^{\infty} \beta^{s-t} \log C_{s} \\
\sum_{s=t}^{\infty}\left(\frac{1}{1+r}\right)^{s-t} C_{s}=(1+r) B_{t}+d_{t} x_{t}+V_{t} x_{t}+\sum_{s=t}^{\infty}\left(\frac{1}{1+r}\right)^{s-t}\left(w_{s} L_{s}-G_{s}\right) \\
\lim _{T \rightarrow \infty}\left(\frac{1}{1+r}\right)^{T} Q_{t+T+1}=0
\end{array}\right.
$$


In (23) we denote $Q_{s+1}=B_{s+1}+V_{s} x_{s+1}$ the value of the individual's financial wealth at the end of period $s$.

The first order conditions for the consumer will be:

1) $\frac{1}{C_{s}}=(1+r) \beta \frac{1}{C_{s+1}} \rightarrow C_{s+1}=(1+r) \beta C_{s}$

that is a difference homogenous first order equation with the solution:

$C_{t}=(1+r)^{s} \beta^{s} C_{0}$

2) $V_{s} \frac{1}{C_{s}}=\left(V_{s+1}+d_{s+1}\right) \beta \frac{1}{C_{s+1}}$

From (25) and (26) we obtain:

$1+r=\frac{d_{s+1}+V_{s+1}}{V_{s}}$

which is a first order nonhomogeneous difference equation, that could be solved recursively, knowing $V_{0}=\frac{d_{0}}{r}$ and the sequence of the dividends:
$V_{s+1}=(1+r) V_{s}-d_{s+1}$

with $d_{s}=Y_{s}-w_{s} L_{s}-I_{s}$, computed in the firm's problem conforming to .

\section{Firm's problem:}

Let us write the dividends as:

$$
d_{s}=A_{s} K^{\alpha}{ }_{s} L^{(1-\alpha)}-w_{s} L_{s}-\left(K_{s+1}-K_{s}\right) \text { : }
$$

The firm will maximize the sum of the dividends:

$$
\max \left(d_{t}+V_{t}\right)=\sum_{s=t}^{\infty}\left(\frac{1}{1+r}\right)^{s-t}\left[A_{s} K_{s}^{\alpha} L_{s}^{(1-\alpha)}-w_{s} L_{s}-\left(K_{s+1}-\right.\right.
$$

The first order conditions for the firm are:

$A_{s} \alpha K_{s}^{\alpha-1} L_{s}^{\beta}=r \quad s \geq t$,

$A_{s} \beta K_{s}^{\alpha} L_{s}^{\beta-1}=w_{s}, s>t$

From (30) and (31), we will determine the values of $K_{s}, L_{s}$ and $Y_{s}$ :

$$
\begin{aligned}
& K_{s}=\left[\frac{r}{A_{s} \alpha}\right]^{\frac{1}{\alpha-1}}\left\{\left[\frac{w_{s}}{A_{s} \beta}\right]^{\frac{(\alpha-1)}{(\alpha-1)(\beta-1)-\beta \alpha}}\left[\frac{r}{A_{s} \alpha}\right]^{\frac{-\alpha}{(\alpha-1)(\beta-1)-\beta \alpha}}\right\}^{\frac{-\beta}{(\alpha-1)}}, \mathrm{s}=1,2, \ldots \\
& L_{s}=\left[\frac{w_{s}}{A_{s} \beta}\right]^{\frac{(\alpha-1)}{(\alpha-1)(\beta-1)-\beta \alpha}}\left[\frac{r}{A_{s} \alpha}\right]^{\frac{-\alpha}{(\alpha-1)(\beta-1)-\beta \alpha}}, \mathrm{s}=0,1,2, \ldots
\end{aligned}
$$

$K_{s}$ and $L_{s}$ will be further used for the determination of $Y_{s}=A_{s} K_{s}{ }^{\alpha} L_{s}{ }^{\beta}, A_{s}$ given by (22), $K_{s}$ given by (32), $L_{s}$ given by (33), $\alpha, \gamma$ estimated parameters, of $I_{s}, d_{s}$ and $V_{s}$.

Using (25) we compute $C_{s}$ and assume that $G_{s}=(1+\delta)^{s} G_{0}$, where $\delta$ is the growth rate of the government expenditures, a political decision parameter and $G_{0}$ is the statistical value for the period 0 .

The trade balance and the burden of the debt in total GDP are computed using (17) and (18).

\section{Grey Two Factors Cobb-Douglas Production Function}

Grey system theory is a method initiated in 1982 by Julong Deng [18] in order to study the models with small databases and partial known information. The systems with lack information are called Grey Systems. In the case of completely unknown information we talk about Black systems, and in the case of completely known information we talk about White systems.

Due to the frequent problems in the macroeconomic data that could lead to errors of estimation, such as high volatility, incompleteness of the series, we use $\operatorname{GM}(1,1)$ 
in order to simulate the data to be used in parameter estimation.

$\hat{Y}, \hat{K}, \hat{L}$ will stand for the $\mathrm{GM}(1,1)$ simulated vectors of $Y, K$. This way grey two factor Cobb-Douglas production function $\hat{Y}_{t}=A_{0}(1+g)^{t} \hat{K}^{\alpha} \hat{L}^{\gamma}$ is obtained. Applying the OLS method, the coefficients of the CobbDouglas grey function were estimated, on the $\mathrm{GM}(1,1)$ approximated data.

\subsection{GM(1,1) Grey Model}

The $\operatorname{GM}(1,1)$ model construction process is described below, according to [19], [20], [21]. Let us consider the sequence $X^{(0)}$ :

$$
X^{(0)}=\left(x^{(0)}(1), x^{(0)}(2), \ldots x^{(0)}(n)\right), n \geq 4, x^{(0)}(i) \geq 0
$$

The sequence $X^{(1)}$ is obtained by applying the accumulated generating operation to $X^{(0)}$ :

$X^{(1)}=\left(x^{(1)}(1), x^{(1)}(2), \ldots x^{(1)}(n)\right)$

$\left[\begin{array}{l}\hat{a} \\ \hat{b}\end{array}\right]=\left(B^{T} B\right)^{-1} B^{T} y$

with:

$$
y=\left[\begin{array}{l}
x^{(0)}(2) \\
x^{(0)}(3) \\
\cdot \\
\cdot \\
x^{(0)}(n)
\end{array}\right], \quad B=\left[\begin{array}{ll}
-z^{(1)}(2) & 1 \\
-z^{(1)}(3) & 1 \\
- & \\
- \\
- \\
-z^{(1)}(n) & 1
\end{array}\right]
$$

The solution $X^{(1)}$ at time $\mathrm{k}$ has the following form:

$$
\hat{x}^{(1)}(k)=\left(x_{1}^{(0)}-\frac{\hat{b}}{\hat{a}}\right)\left(1-e^{\hat{a}}\right)\left(e^{-\hat{a}(k-1)}\right), \quad k=2,3, \ldots,
$$

\section{Empirical Study}

\subsection{The Classic Approach}

Because the employment in Romania decreased due to lower birth rates and increased labor migration, we approximated labor input using the method proposed by Altar et al. [22]:

$$
L_{t}=N_{t} q_{t}\left(1-u_{t}\right) H_{t}
$$

$N$ stands for the HP filtered of the active civil population, $q$ is the HP filtered participation where:

$x^{(1)}(k)=\sum_{j=1}^{k} x^{(0)}(j), k=1,2, \ldots, n$

It is obvious that $X^{(1)}$ is monotonically increasing.

The generated mean sequence $Z^{(1)}$ is defined as:

$Z^{(1)}=\left(z_{2}^{(1)}, z_{3}^{(1)}, \ldots z_{k}^{(1)}\right), \quad k=2,3, \ldots$

where:

$z^{(1)}(k)=\lambda x^{(1)}(k)+(1-\lambda) x^{(1)}(k-1), k=2,3, \ldots n$

(generally $\lambda=0,5$ )

The following equation for $X^{(1)}$ represents the whitening equation:

$\frac{d x^{(1)}}{d t}+a x^{(1)}=b$

Parameter $a$ is called the developing coefficient and parameter $b$ is called the grey input coefficient. The difference equation: $x^{(0)}(k)+\hat{a} z^{(1)}(k)=\hat{b}$ is written as: 
The

relation

$Y_{s}=A_{s} K_{s}^{\alpha} L^{\gamma}{ }_{s}=A_{0}(1+g)^{s} K_{s}^{\alpha} L_{s}^{\gamma} \quad$ expressed in terms of indices is: $I_{Y_{s}}=A_{0}(1+g)^{s} I_{K}^{\alpha} I_{L}^{\gamma}$.

Taking the logarithm: $\ln I_{Y_{s}}=\ln A_{0}+s \ln (1+g)+\alpha \ln I_{K}+\gamma \ln I_{L}$

The estimators obtained are:

$\alpha=0,39135, \gamma=0,25789, A_{0}=301,3796,(1+g)=1,01357$.

We consider the estimators acceptable, because they verify the significance level test, and $\mathrm{R}$ square $=0.933621461$ reveal that the model replicate well the economic phenomena.

The degree of homogeneity is given by the sum of the two elasticity: $\alpha+\gamma=0,6492<1$ so, multiplying with $\lambda>0$ the two production factors, the production will increase with $\lambda^{0,6492}$, $g=0,01357$ the total productivity growth rate, is small, which reveals that in terms of technical progress implemented in production, there are great resources in Romania. All the parameters are economically acceptable.

We considered $\mathrm{r}=0.034$, the average world interest rate (HomeFinance.nl, 2013), and $\beta$ $=0.968$ as the consumer's discount factor, computed as the inverse of the expected inflation index that follows an adaptive expectations mechanism.

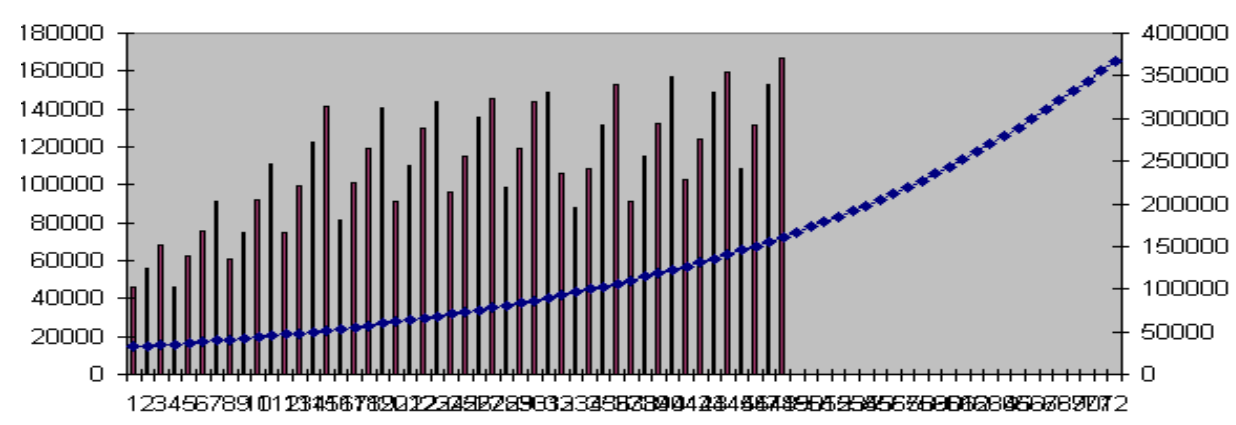

$\rightleftarrows$ Actual real GDP
$\multimap$ Computed real GDP

Fig. 1. Real GDP: actual, computed, and predicted for 2014Q3-2018Q4.

We notice a high volatility of the actual real GDP, caused by the economic processes generated by the readiness to enter the EU, post-accession processes, but also the economic crisis crossed by Romania in-Tre 2008-2010.

The period 2004Q1-2005Q4 was characterized by an extensive investment process in Romania, having the effect of the continuous increase of the capital/GDP ratio. The recent crisis in Romania during 20082010Q4, was manifested by decreased values of real GDP and other macroeconomic indicators. The last quarter of the year 2010 took place an economic recovery.
Unfortunately, the delayed effects of the global economic crisis that were appointed "hysteresis", is present also in the economic processes in Romania, which is manifested by a very slow recovery process. The predicted values of the macroeconomic indicators have positive, but reduced values of the growth rates. The reduction of the capital accumulation and the reduction of potential GDP took place. The last year of the forecasting reveals the increase of the growth rate that will have an average of $4.12 \%$ in 2018, higher than the capital growth rate marking a predominantly intensive character of the Romanian economy. 


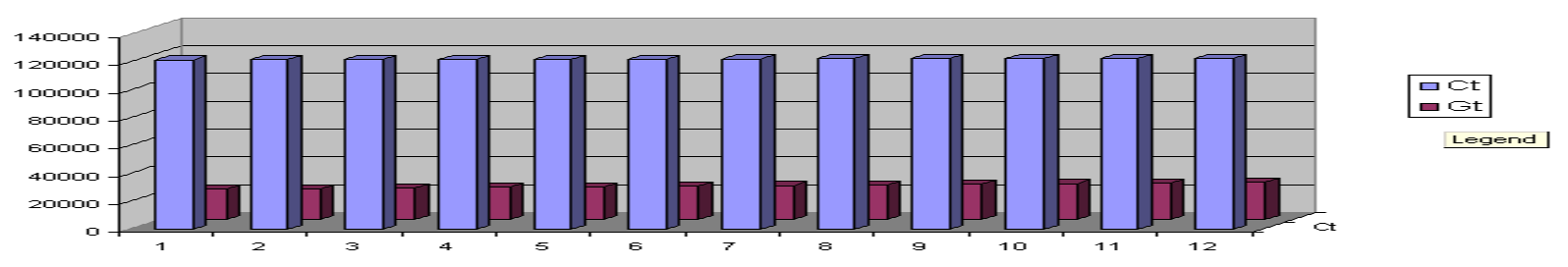

Fig. 2. The forecast of the Consumption and of the Government Expenditures in the period 2014Q3-2018Q4.

The growth rate of the government The path of the government expenditures is: expenditures was a simulation parameter. We considered finally $\delta=0.0193$, that was used also in our previous work, because it assure simultaneously the decrease of the debt /GDP ratio and the social economic and objectives

$G_{t}=(1+\delta)^{t} G_{0}=1.019^{t} \times 21384,9636 \times 10^{9}$, considering the initial value $G_{0}=21384.9636 \times$ $10^{9}$ (National Institute of Statistics, 2013). of the government.

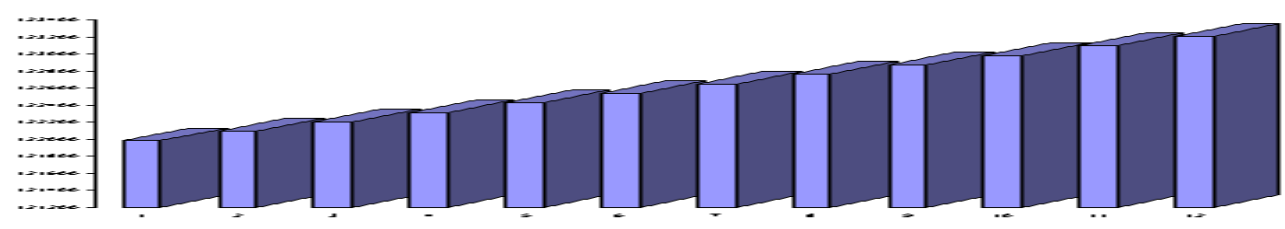

르도

Fig. 3. The forecasting of the Consumption during 2014Q3-2018Q4

The growth rate of the consumption is computed using the Euler equation of the consumption based on the international interest rate and on the discount factor.

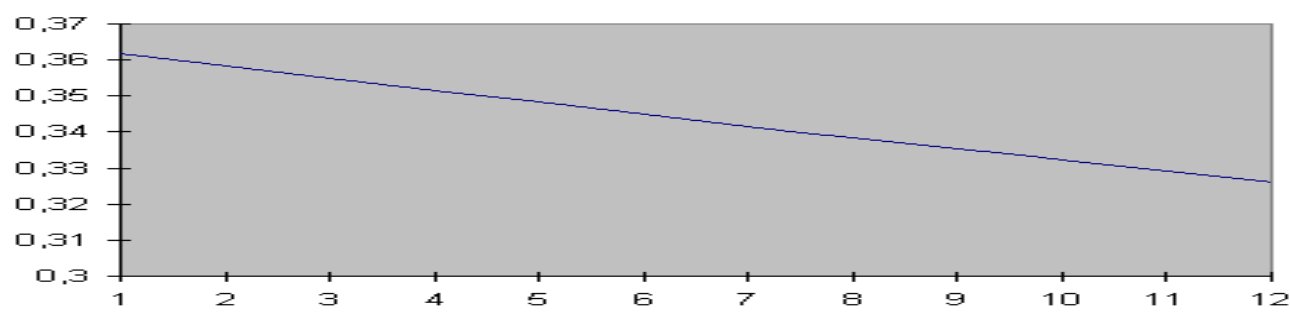

Fig. 4. The forecasting of the debt/GDP ratio during 2014Q2-2018Q4.

We can see that the debt/GDP ratio is decreasing that will result in the reduction of the current account deficits assuring further government solvability.

Due to ample variations of the gross investments data, we applied the HP filter to the gross investments data separating the trend that was used as input data to compute the production function parameters. We identified also the cyclical component of that data series, the result could be shown in the figure 5 . 


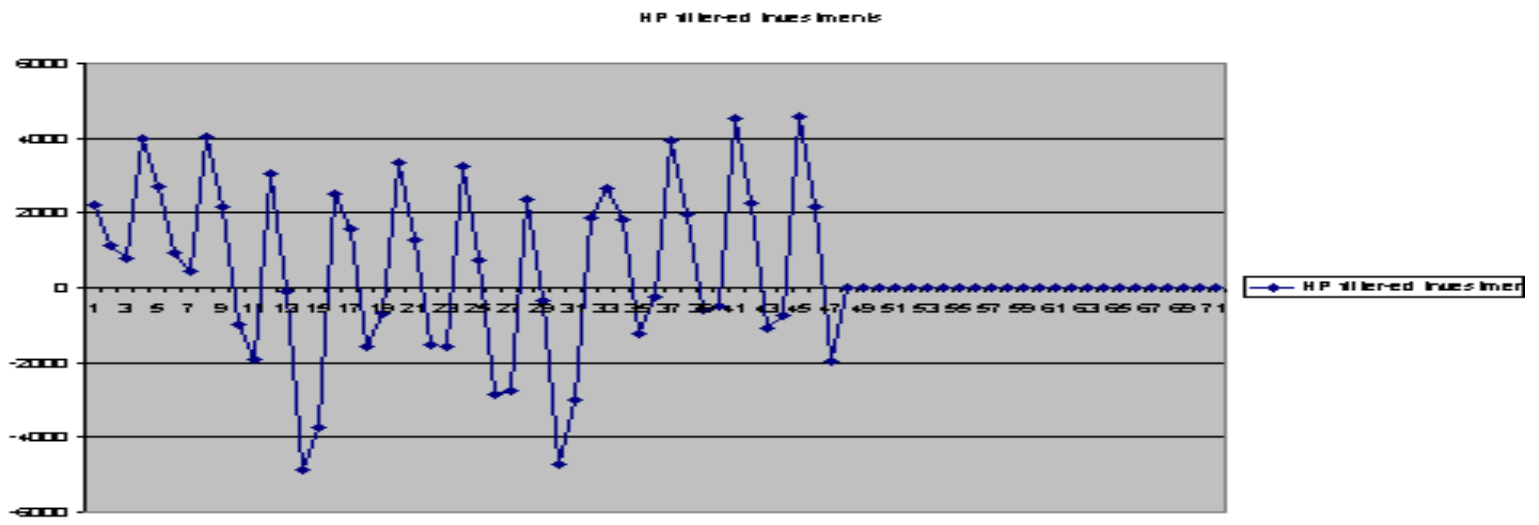

Fig. 5. Actual real gross investments data

Gross investments cyclical variation can be sizeable up to 4000 monetary units in both

directions of the trend. Clearly visible is the period of recession between 2008 and 2010.

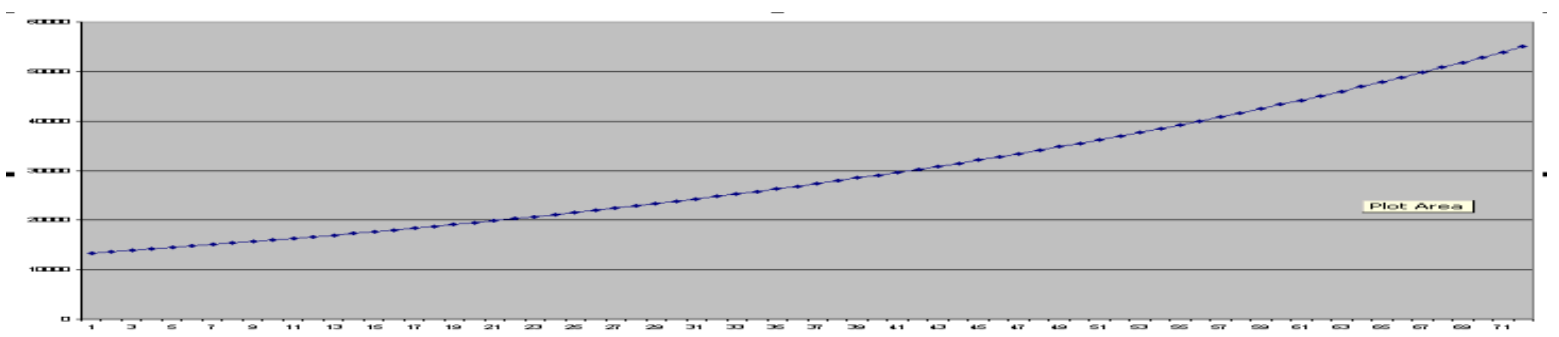

Fig. 6. Computed and predicted 2014Q3-2018Q4, Gross Investments

The prediction of gross investments using representative agent model show an increase in gross investments between 2014Q32018Q4 with $3,67 \%$, that is lower than predicted GDP growth rate, that is the capital /output ratio, growth rate is decreasing, meaning the growing productivity of capital.

\subsection{The Grey Approach}

Using quarterly data for real GDP, for the real gross capital formation, and for the working hours of the employed population, between 2000Q1 and 2014Q2, we determined the grey data series, following $\operatorname{GM}(1,1)$ grey algorithm. Constructing the indexes series, and applying the same logarithm as in the preceding case, we estimated the parameters of the CD production function, obtaining the grey production function:

$$
\hat{Y}_{t}^{\text {calc }}=513,7152(1,11379)^{t}\left(\hat{K}_{t}^{\text {grey }}\right)^{0,31946}\left(\hat{L}_{t}^{\text {grey }}\right)^{0,13578}
$$

First we notice that the two elasticity are smaller than those obtained in the first estimation, instead the scale parameter is higher. The production function has a degree of the homogeneity is: $\alpha+\gamma=0,31946+0,13578=0,4552$, and a productivity growth rate $\mathrm{g}=0,11379$ higher than in the case of the previous estimation.
In order to apply the model and to compute the macroeconomic indicators, we used the same average world interest rate $r$ and discount factor $\beta$, as in the case of the model based on actual data.

The computed the real GDP data series using estimated parameters, are compared with the actual data series (Figure 7), and then is computed a 5-year prediction 


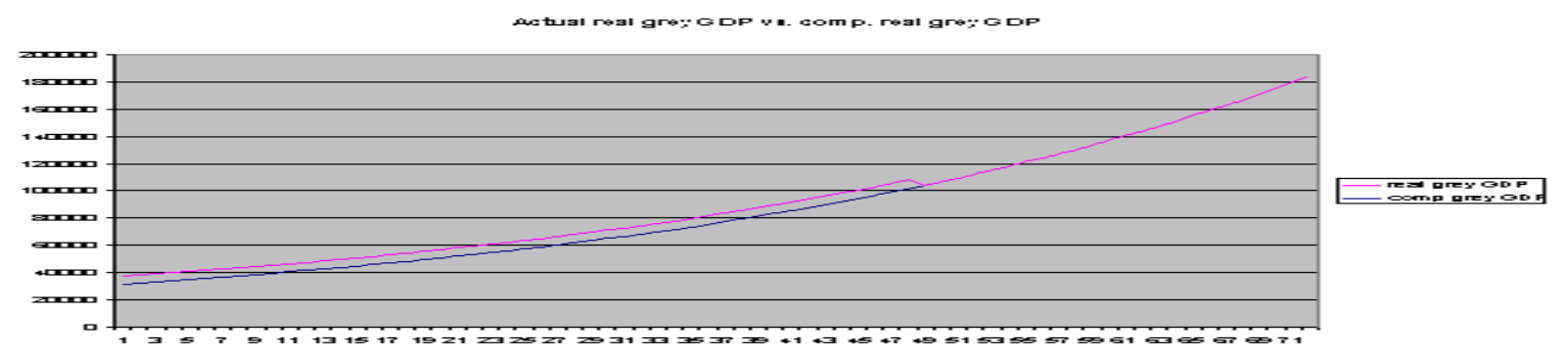

Fig. 7. Grey real GDP: actual, computed and predicted data

Using analytical expressions of the main indicators of model, we also computed consumption and government expenditures (Figure 8).

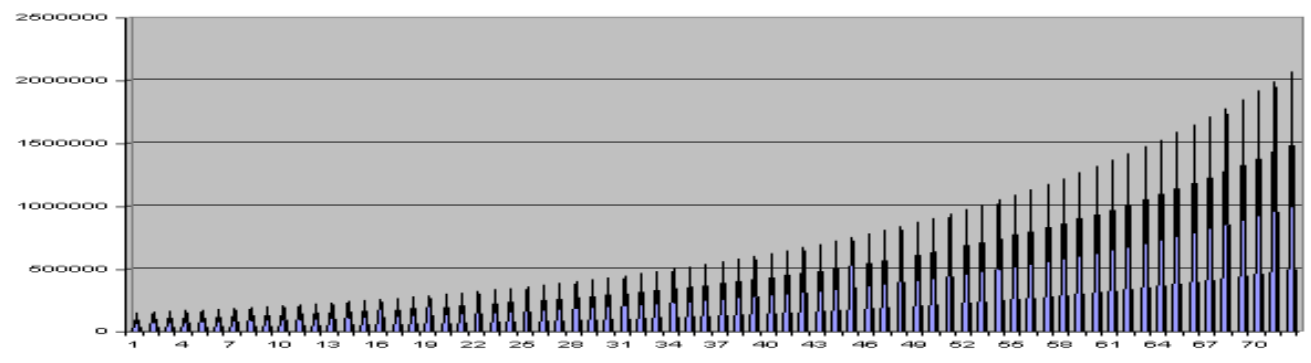

ERrey oov. Expenditur
Borey consumption

Fig. 8. Actual, computed and predicted (2014Q3-2018Q4) grey consumption and government expenditures.

The government expenditures were simulated using the same growth rate and the initial value, as in the case of the model applied to the actual data.
The intensive character of the economy is even proved by the growth rate of the grey gross investments of $3.12 \%$ that is lower than the grey GDP growth rate of $3.987 \%$.

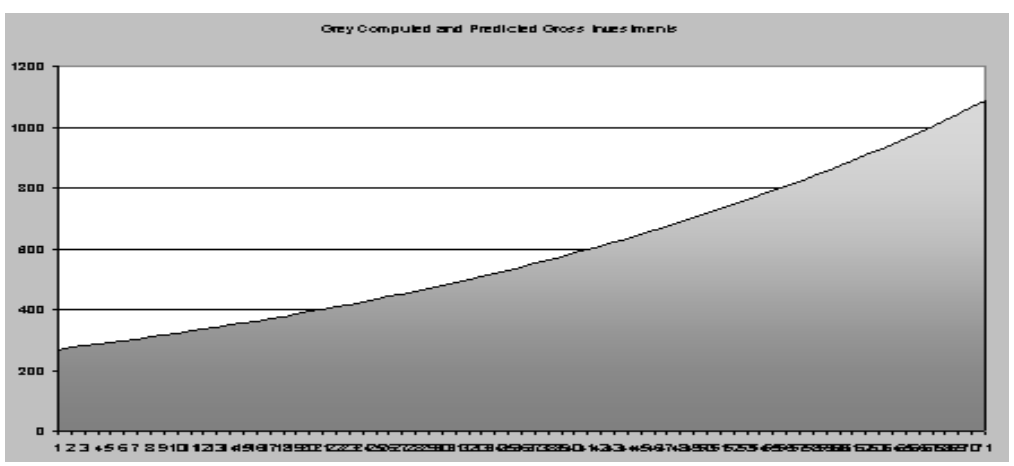

Fig. 9. Computed and Predicted 2014Q3-2018Q4 Grey Gross Capital Formation

We mention that the predicted grey real gross capital formation has a reduced growth rate than in the case of the prediction based on the actual data, this having the effect of a lower growth rate than the ratio capital / GDP and so a productivity growth rate, even higher.

\section{Conclusions}

In the empirical work we used quarterly data for GDP, gross capital formation and active civil population expressed as hours worked, with the algorithm presented above.

Due to important fluctuations in the original data representing the gross capital formation, we applied the HP filter to the original data, 
and remarked a high volatility of the data, sized between -4000 and 4000 monetary units, the limits values being reached especially during 2008-2010 during the economic crisis in our country.

Due to the increase of the gross investments growth rate, 2014Q3-2018Q4 (3.67\%), the productivity of the capital grew in that period. The absence of the adequate data for the stock of the capital for Romania, determined us to use $\operatorname{GM}(1,1)$ adjustment of the data and grey production function approach.

Regarding the two approaches, we observe some common features:

- the increasing growth path of GDP, consumption, investments, with different growth rates and a decreasing rate of the burden of debt;

- predicted annual GDP growth rate is higher than gross investments one, that proves a rise of the productivity of the capital and accordingly to a decreasing capital output rate;

- the results indicate a slow increase in the growth rate of output after the third quarter of 2010, that followed the decline in 2008Q4 and 2010Q2. For the period 2004Q2-2007Q3, the main driving forces in the GDP growth were the technical progress, and the contribution of the physical capital.

\section{References}

[1] M. Grabner, "Representative agents and the microfoundations of macroeconomics," Seminal paper, Institute for Advanced Studies, Vienna, Austria, 2002.

[2] L. P. Hansen and T. Sargent, "Formulating and estimating dynamic linear rational expectations models, " Journal of Economic Dynamics and Control, vol. 2, pp. 7-46, 1980.

[3] J. E. Hartley, The Representative Agent in Macroeconomics. New York: Routledge, 1997.

[4] A. P. Kirman, "Whom or what does the representative agent represent?," Journal of Economic Perspectives, vol. 6, pp.
117-136, 1992.

[5] S. An, C. Yongsung and Kim Sun-Bin, "Can a representative-agent model represent a heterogeneous agenteconomy," Economic Journal: Macroeconomics, vol. 1, no. 2, pp. 29-54, 2009.

[6] N. G. Mankiw, J. J. Rotemberg and L. H. Summers, "Intertemporal substitution in macroeconomics," Quarterly Journal of Economics, vol. 100, no. 1, pp. 225-251, 2005.

[7] D. Backus, M. Chernov and S. Zin, "Sources of entropy in representative agent models," The Journal of Finance, vol. 69, no. 1, pp. 51-99, 2014.

[8] A. Maussner, "CoRRAM: Computing Recursive Representative Agent Models,", 2009, Available: http://dge.repec.org/codes/maussner/CoR RAM.rar

[9] D. Krueger, Quantitative Macroeconomics: An Introduction. 2007. Available:

http://down.cenet.org.cn/upfile/8/200851 785232169.pdf

[10] J. Ferber, Les Systèmes Multi-Agents. Vers Une Intelligence Collective. Paris: InterEditions, 1995.

[11] F. Billari, T. Fent, A. Prskawetz and J. Scheffran, "An introduction in agentbased computational modelling: an introduction," in Agent-Based Computational Modelling to Economics, pp. 1-16, 2006.

[12] C. M. Macal and M. J. North, "Tutorial on agent-based modeling and simulation," in Proc. WSC'05 of the $37^{\text {th }}$ Conference on Winter Simulation, 2005, pp. 2-15.

[13] D. Acemoglu, "Economic growth: overlapping generations", EC 14, MIT, 2011.

[14] A. Andrei, S. Stancu, I. Georgescu and A. M. Constantin, "Open economies representative agent models: empirical application for Romania," in Proc. 2013 AASRI International Conference on Social Sciences, Singapore, 2013, pp. 159-164. 
[15] A. Andrei, A. Bădescu and I. Georgescu, "A grey approach to open economies representative agent models: empirical study for Romania," in Proc. 2014 International Conference on Economic Informatics, Bucharest, Romania, 2014, pp. 525-529.

[16] M. Obsfeld and K. S. Rogoff, Foundations of International Macroeconomics. Massachussets: MIT Press, 1996.

[17] S. Honkapohja, "Open economies and international financial markets," FPPE/KAVA, 2001.

[18] J. Deng, "Introduction to grey system theory," The Journal of Grey System, vol. 1, no. 1, pp. 1-24, 1989.

[19] L. Ruo-qi, Z. Tao and X. Shi-lian, "The combination forecasting model based on the gray system GM $(1,1)$ and its application in the economic field," Lecture
Notes in Information Technology, vol. 12, pp. 313-318, 2012.

[20] D. Zhou, "Optimization modelling for $\operatorname{GM}(1,1)$ model based on BP neural network", International Journal of Computer Network and Information Security, vol. 1, pp. 24-30, 2012.

[21] S. Liu, J. Forrest and Y. Yang, "Advances in grey systems research," The Journal of Grey System, vol. 5, no. 2, pp. 1-18, 2013. [22] M. Altar, C. Necula and G. Bobeică, "Potential GDP for the Romanian economy. An eclectic approach," Journal for Economic Forecasting, vo. 0(3), pp. 5$25,2010$.

[23] A. Imperato, G. Oprescu and A. Andrei, "Optimal predictor of inflation. The optimal Kalman filter," Economic Computation and Economic Cybernetics Studies and Research, vol. 36, pp. 69-77, 2003.

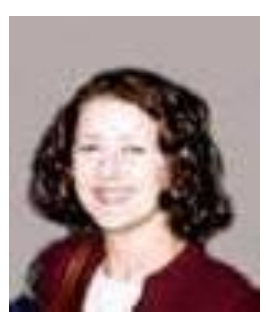

Ana Michaela ANDREI has graduated the Faculty of Economic Computation and Economic Cybernetics. Currently she is a full Professor within the Department of Economic Informatics and Cybernetics at Faculty of Cybernetics, Statistics and Economic Informatics from the Bucharest University of Economic Studies. She teaches courses on Economic Cybernetics, Quantitative Macroeconomics, Public Sector Economics, Economic Dynamics, General Equilibrium Theory, Quantitative Microeconomics. She is a doctoral advisor, member of the Romanian Society of Econometric and a member of the Scientist Academy.

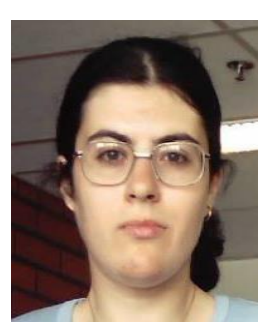

Irina GEORGESCU holds a $\mathrm{PhD}$ in Economics from Turku Centre for Computer Science, Åbo Akademi, Turku, Finland. Currently she is with the Department of Economic Informatics and Cybernetics at Faculty of Cybernetics, Statistics and Economic Informatics from the Bucharest University of Economic Studies. Her research interests lie in the area of fuzzy sets and systems, social choice and welfare and risk theory. She has published 2 books in Springer Verlag and about 30 journal papers on fuzzy choice functions and possibilistic risk theory. 